\title{
Turizmin Yerel Kalkınmadaki Öneminin Değerlendirilmesi: Van Kenti Örneği ${ }^{1}$
}

DOI: 10.26466/opus.597619

\begin{abstract}
*
\section{Vedat Y1lmaz* - Mazlum Karaağaç**}

*Dr. Öğr. Üyesi, Van Yüzüncü Yıl Üniversitesi İ̈BF Kamu Yönetimi Bölümü, Van/Türkiye E-Posta: vedatyilmaz1977@gmail.com

ORCID: 0000-0003-4624-9824

** Yüksek Lisans Mezunu, Van Yüzüncü Yıl Üni., İ̈BF Kamu Yönetimi Bölümü, Van/Türkiye E-Posta: mazlumkaraagac21@outlook.com

ORCID: 0000-0001-7540-4171

\section{Öz}

Günümüz şehirlerinin kendi kimlikleriyle ön plana çıkmalarılla birlikte, uluslararası piyasada rekabet edebilirliğinin güçlendiği, her kentin kendi simge ve değerleriyle pay alma yarışının uluslararası alanda geçerlilik kazanması yadsınamaz bir gerçeklik haline bürünmekte olduğu şu günlerde, yerele ait değerler ulusal ve küresel ölçekte pazarlanarak katma değerler ortaya çıkarmaktadır. Yerel ekonomik kalkınma, kısaca bir bölgeye özgü dönüşüm süreçlerinin dinamik olarak harekete geçirilmesi olarak tanımlanmaktadır. Bu dönüşüm ekonomik karar alıcılarını, ekonomik hususlarda merkezi otoritenin güçlü ve tek olduğu klasik yönetim anlayışından yerel öncelik ve karar mekanizmalarının önem kazandığı yerel kalkınma anlayışına sevk etmiştir. Yerel Ekonomik Kalkınma (YEK) süreci için yöre ekonomisinin sektörel analizlerinin yapılması, öncelikli ve sürükleyici sektörün belirlenmesi gerekmektedir. Yerel ekonomik kalkınma sosyal, kültürel, ekonomik ve çevresel parametrelerin birlikte gelişimini ifade etmektedir. Bu yönüyle tüm bu parametreleri bünyesinde barnndıran turizm sektörü YEK sürecinin lokomotifi olarak görülmektedir. Van kenti özelinde, sanayi ve tarım sektörünün istenilen düzeyde olmadı̆̆ mevcut ekonomik göstergelerden de anlaşılmaktadır. Van destinasyon bölgesi için turizmin mevcut potansiyel varlı̆̆ı ve bunun ekonomik bir değere dönüşmesinin sağlanması yani turizmin geliştirilmesi yerel ekonomik kalkınma için firsat mıdır? Anlayışı üzerinden hareket edilmektedir. Bu bağlamda çalışmanın amacı, Van ilinin kalkınmasında turizmin etkisi ölçülerek genel bir çerçevenin çizilmesidir. Bu bağlamda 300 İranlı turist ile anket çalışması yapılmıştır.
\end{abstract}

Anahtar Kelimeler: Kent, Kalkınma, Turizm, Van

\footnotetext{
${ }^{1}$ Bu çalışma Mazlum KARAAĞAÇ tarafından Temmuz 2019'da Van Yüzüncü Yıl Üniversitesi Sosyal Bilimler Enstitüsü Kamu Yönetimi Anabilim Dalında hazırlanan "Turizmin Yerel Kalkınmadaki Önemi: Van Örneği" başlıklı yüksek lisans tez çalışmasından güncellenerek hazırlanmıştır.
} 


\title{
Evaluation of The Importance of Tourism in Local Development: The Case of Van City
}

\begin{abstract}
With the emergence of today's cities, with their own identities, their competitiveness in the international market is strengthened, and the fact that each city's share of their own symbols and values becomes valid in the international arena becomes an undeniable reality. Local economic development is defined as the dynamic mobilization of a region-specific transformation process. For the Local Economic Development (LED) process, sectoral analyzes of the local economy should be made and the priority and the driving sector should be determined. Local economic development refers to the co-development of social, cultural, economic and environmental parameters. In this respect, the Tourism sector, which incorporates all these parameters, is seen as the locomotive of the LED process. It is understood from the current economic indicators that the industrial and agricultural sector is not at the desired level in Van. Is the existing potential for tourism available for the destination of Van and its transformation into an economic value, ie the development of tourism, is an opportunity for local economic development? We are moving through understanding. In this context, the aim of the study is to draw a general framework by measuring the impact of tourism on the development of Van. In this context, surveys were conducted with 300 Iranian tourists.
\end{abstract}

Keywords: City, Development, Tourism, Van 


\section{Giriş}

Küreselleşme süreci ile birlikte yaşanan sosyo-ekonomik değişimdönüşüm uluslararası, ulusal ve yerel düzeyde gelişmişlik farklılıklarının belirgin bir şekilde ortaya çıkmasına neden olmuştur. Ülkeler arası rekabetin hızla yükseldiği çağımızda hem gelişmiş ülkeler hem de gelişmekte olan ülkeler özgün değerleri ile fırsatları değerlendirerek yerel-ulusal menfaatlerin geliştirilmesi ve korunması bakımından yerel ölçüde kalkınma girişimlerini öncelikli hedef haline getirdikleri görülmektedir. Kalkınma anlayışının ilk yıllarından itibaren uygulanan klasik kalkınma anlayışı küreselleşme süreci ile birlikte bir dönüşüm sürecine girmiştir. Bu dönüşüm ekonomik karar alıcıları, ekonomik hususlarda merkezi otoritenin güçlü ve tek olduğu klasik yönetim anlayışından yerel öncelik ve karar mekanizmalarının önem kazandığı yerel kalkınma anlayışına sevk etmiştir. Günümüz şehirlerinin kendi kimlikleriyle ön plana çıkmalarıyla birlikte, uluslararası piyasada rekabet edebilirliğinin güçlendiği, her kentin kendi simge ve değerleriyle pay alma yarışının uluslararası alanda geçerlilik kazandığı yadsınamaz bir gerçeklik haline dönüşmektedir. Uluslararası konjonktürde makroekonomik kalkınma stratejisinden mikro temelli bir yerel ekonomik kalkınma stratejisine doğru dönüşüm süreci yaşanmaktadır.

Dünyanın gelişmiş ve gelişmekte olan ülkelerinde olduğu gibi Türkiye'de de yerel-bölgesel gelişmişlik farkları bulunmaktadır. Yerel ekonomik kalkınma politikaları ile geri kalmış alanlarda sosyo-ekonomik dengesizlikler giderilebilmektedir. Yerel kaynakların en etkin kullanılacağı sektörün belirlenmesi sektör seçiminin önemini ortaya koymaktadır. Turizm sektörü, yer aldığı bölgenin Gayrı Safi Yurtiçi Hasılasına (GSYH) olumlu katkıları, çarpan etkisiyle pek çok sektörün gelişmesine ve bu sektörlerdeki istihdamın artmasına, döviz girdilerindeki artış oranlarıyla gerek yerel bazda gerekse de ülke ekonomisine katkılarıyla önemli bir sektör konumundadır.

$\mathrm{Bu}$ bağlamda çalışmanın amacı, turizmin yerel ekonominin kalkınmasındaki rolünü Van kenti özelinde analiz etmektir. Ayrıca turizmin yerel ekonominin kalkınmasında sağladığı etki ve kentin sahip olduğu alternatif turizm potansiyeli ortaya konularak bu potansiyele 
ilişkin kentte ekonomik ve sosyal kalkınmanın sağlanmasında turizmin önemini vurgulamak hedeflenmiştir.

Çalışmada, Van kentini ziyarete gelen İranlı turistler ile 2018 Kasım2019 Nisan ayları arasında 300 anket çalışması yapılmıştır. Yapılan anket çalışmasıyla turizmin kentin ekonomisine katkısı ölçülmeye çalışılmış ve ortaya çıkan sonuç çerçevesince bazı öneriler sunulmuştur. Çalışmada toplanan veriler SPSS 19.0. programı ile analiz edilerek yorumlanmıştır.

\section{Yerel Ekonomik Kalkınma}

Yerel kalkınma kavramının tanımlamasının yapılabilmesi için öncelikli olarak "yerel" kavramının tanımına değinilmesi daha doğru olacaktır. "Yerel" sözlük anlamıyla yöresel anlamını taşımaktadır. "Yerel", hem içinde yaşayan insanların yaşamlarını sürdürmesi için bir çevre oluşturması, hem de bu çevrede yaşayanların kapasitelerinin belirlenmiş olması açısından önem teşkil etmektedir (Tekeli, 2002, s.8). Yerel ekonomik kalkınma anlayışının ön plana çıkmasında çok farklı gelişmelerin rol almasından kaynaklı ilgili alan yazınında genel kabul gören bir tanımlaması yoktur ve oldukça farklı tanımlamalara rastlamak mümkündür. Yerel Ekonomik Kalkınma (YEK) yaklaşımı eskide bir bölge veya alanda diş sanayi yatırımlarının bir bölgeye çekilmesi olarak tanımlanmıştır. Uzun bir dönem için geçerli olan bu geleneksel yaklaşımda büyük oranda iş sahalarını geliştirecek sanayi yatırımlarını geliştirecek sanayi yatırımlarını bir bölgeye çekmeyi hedefleyen teşvik ve primlerden meydana gelen bir strateji olarak görülmüştür (Gül, 2004, s.204). YEK, yerel halkın sosyo-ekonomik ve kültürel anlamda gelişmesini sağlamaktır. Diğer bir ifadeyle "yerelin yaşam kalitesini bir üst seviyeye çıkarma çabası" olarak tanımlanabilir (Atmaca, 2018, s.428; Tunçsiper ve Yılmaz, 2009, s.54).

Yerel kalkınma düşüncesi, “yerel olanın ön: plana çıtığı, yerel dinamiklerin harekete geçirilerek, yerel toplulukların sosyal, ekonomik, politik ve kültürel alanlarda sürdürülebilir kalkınma ilkelerine de uygun olarak gelişimini sağlamayı amaçlayan bir anlayışı" açıklamaktadır. Yerel ekonomik kalkınmanın amacl, yerel paydaşların ve toplulukların bahse konu olan alanlarda ilerlemek adına eş güdüm halinde hareket ederek güçlerini birleştirmeleri, merkezi ve ademi merkezi yönetimlerin 
bu harekete destek olmalarıdır (Pektaş, 2010, s.7). Bir başka ifadeyle yerel ekonomik kalkınma (YEK) kavramı; yerel, şehir, metropol ve alt-ulusal bölge gibi farklı ölçeklerde tanımlanan alanlarda toplumun yaşam standartlarını yükselten ve ekonomik faydayı arttıran, ekonomik gelişme ve büyümeyi sürdürülebilir kılmak için yerel yönetimlerin, özel işletmelerin, sivil toplum kuruluşlarının ve yerel halkın amaçlarını gerçekleştirmeye yönelik olarak çalışmasını sağlayan bir süreç olarak tanımlanmaktadır (Özmen, 2007, s.1).

Yerel ekonomik kalkınma kavramı için yapılmış pek çok tanımdan hareketle YEK sürecinin en önemli ortak özellikleri şöyle sıralanabilir (Tunçsiper ve Yılmaz, 2009, s.54):

- Yerel ekonomik kalkınmanın lokomotifi girişimciliktir.

- Yerelin özgün değerlerini ve kaynaklarını akılcı kullanması gerekmektedir. Yerelde tüm paydaşlarla iş birliğine gidilmesi gerekmektedir. YEK sürecinin başarıya ulaşabilmesi özel işletmelerin, kamunun, kar amacı gütmeyen kuruluşların ve halkın birlikte hareket etme kabiliyetine bağlıdır.

- Kalkınma hamlesi uzun süreli ve sürdürülebilirlik ilkesi temelinde benimsenmelidir.

- İşleyen ve dinamik bir yönetim anlayışı zorunlu görülmektedir.

\section{Turizm ve Yerel Ekonomik Kalkınma İlişkisi}

Yerel ekonomik kalkınmayı olumlu yönden etkileyen sektörlerden biri de turizm sektörüdür. Ülkelerin herhangi bir kentinde turizm olanaklarının gelişmesi, o kentin diğer kentlerle arasındaki dengesizliklerin de azalması anlamina gelmektedir. Turizmin gelişmesiyle birlikte geri kalmış kentin ekonomisine yeni kaynaklar aktarılacak, yeni iş alanları ve istihdam sahaları oluşacak ve bölge ekonomisinin her sektörde sağlayacağı katma değer buna paralel olarak artacaktır. Bununla birlikte turizmin yerel ekonomik kalkınma sürecinin etkilerinin belirlenmesinde ekonomik faydaların yanı sıra yaşam kalitesinin artması, sosyo-kültürel varlıkların korunmasına, yerel kültürlerin önemine, karşılıklı kültürel değişime ve alt ve üst yapı olanaklarının gelişmesine katkılar sağlamaktadır. Tüm bu olumlu etkilerinin yanında birtakım olumsuz özellikleri de bulunmaktadır. Çevre kirliliği, doğanın ve arkeolojik alanların 
tahrip edilmesi, arazi kullanım sorunları, yerel halkın ayrıcalıklarının azalması gibi etkileri bulunmaktadır.

Yerel-bölgesel ekonomik kalkınma aşamaları incelendiğinde, kalkınma hamlesi içerisinde olan ülkelerde eskiden ekonomi içerisinde tarım sektörünün önemli bir paya sahip olduğu, geçen süre içerisinde hizmet ve sanayi sektörlerinin paylarında tarım sektörünü aşan önemli büyümeler olduğu görülmektedir. "Küreselleşme olgusu; ulaşım, iletişim ve bilgi teknolojisindeki baş döndürücü gelişmeler, iktisadi kalkınmanın ne tarım ne de sanayi sektörü ile gerçekleştirilemeyeceğini göstermiştir. Bu bağlamda, sektörel bazda zenginlik ve katma değer yaratan en önemli sektör artık hizmetlerdir" (Bahar, 2007, s.2). Tüketici tercihlerinin son dönemdeki değişimleri, refah seviyesinin yükselmesi sonucu artan mekânsal hareketliliğe paralel olarak gelişen hizmete dayalı sektörlerde ciddi gelişmeler yaşanmaktadır. Bu bağlamda dünyanın birçok bölgesinde hızlı bir gelişme trendi içerisinde olan ve ekonomik büyümenin gerçekleşmesinde ciddi etmenleri olan sektörlerden birisi kuşkusuz turizm sektörü olmuştur (Eceral ve Özmen, 2009, s.47). Kalkınma sürecini başarı ile tamamlamış olan ülkelerde turizmin yerel kalkınmayı ve dolayısıyla bölgelerarası dengesizliğin önlenmesi noktasında önemli bir rol alabileceği kabul edilmiştir. Kalkınma sürecindeki ülkelerde yerel kalkınma stratejileri içerisinde turizm potansiyeline sahip olan kentlerin gelişmesi için turizm sektörünü bir araç olarak görmeye başlamışlardır (Hao vd., 2003'den aktaran Tunçsiper ve Yılmaz, 2009, s.56).

\section{Turizm Kavramı}

Turizm ve turist kelimelerinin etimolojik kökenlerine öncelikli olarak bakılacak olursa: Turizm, Latince kökenli bir sözcüktür. Latince'de dönme hareketini ifade eden "tornus" kelimesinden tour (İngilizce ve Fransızca) sözcüğü türetilmiştir. Tour sözcügüu, "hareket edilen yere dönmek şartıyla yapılan seyahat" anlamına gelmektedir. Turizm sözcüğü ise "tur yapan" anlamina gelen "tourist" (turist) ve "tour" kelimelerinden doğmuştur (Hazar, 2006, s.3).

Turizm olayını ve kavramını tanımlamak amacıyla yapılan araştırmalarda literatür çalışmaları incelendiğinde, XIX. yüzyılın sonlarına kadar 
uzandığı görülmektedir. Olaya farklı yönleriyle bakan düşünürler farklı tanımlamalar yapmışlardır. Yapılan tanımlardan bazılarına örnek vermeden önce Guyer-Feuler tarafından ilk defa turizm tanımı 1905 yılında ortaya atılmıştır. Fueler'e göre: “Turizm artan hava değişimi ve dinlenme gereksinmeleri, doğa ve sanatla beslenen göz alıcı güzellikleri tanıma isteğine; doğanın insanlara mutluluk verdiği inancına dayanan ve özellikle ticaret ve sanayinin gelişmesi ve ulaşım araçlarının kusursuz hale gelmelerinin bir sonucu olarak ulusların ve toplulukların birbirlerine daha çok yaklaşmasına olanak veren 'modern' çağa özgür bir olayıdır" (Kozak vd., 2000, s.1). Turizm; insanların dinlenmesini sağlayan, yeni yerleşimler görmek ve tanımak düşüncesiyle kültürel anlamda geliştirici faaliyetler olmasının yanında yeni işgücü olanakları oluşturan, özellikle yöresel anlamda ekonomik kalkınmaya katkı sunan ve bu yolla yöresel büyümeye hız kazandıran faaliyetlerdir (Gürer, 2003, s.29). Dünya Turizm Örgütü (WTO) turizmi: "insanların yaşadıkları çevrenin dışındaki bir yerde yirmi dört saatten az ve bir yıldan fazla kalmamak şartıyla eğlence iş sağllk ve boş zaman ve spor gibi çeşitli amaçlarla gerçekleştirdiği faaliyetler" olarak tanımlamıştır (WTO, 1995, s.15).

\section{Türkiye Ekonomisinde Turizmin Yeri ve Etkileri}

Türkiye'nin ekonomisinde turizmin önemine değinmeden evvel ekonominin ve turizm ekonomisinin tanımına bakılacak olursa; ekonomi, insanların sınırsız arzularını karşılayan sınırlı (kıt) kaynaklar arasında yaptıkları tercihleri anlamaya ve açıklamaya çalışan bilim dalıdır (İçöz, 2005, s.8). Turizm ekonomisiyse, turizm faaliyetinin sebeplerini, kapsamını, gelişme şartlarını, sonuçlarını, bu olaylar arasındaki neden-sonuç ilişkilerini bilimsel yöntemlerle ekonomik açıdan irdeleyerek turizm olayının bağlı olduğu kanun ve ilkeleri ortaya çıkaran bir disiplindir (Olalı ve Timur, 1986, s.195).

Turizm ekonomisi literatüründe istihdam denildiğinde akla gelen ilk anlamı şüphesiz, emek-yoğun veya yakın anlamda kullanılan işgücü ile ilişkilidir. Bu nedenle İstihdam teriminin ekonomi bilimindeki tam istihdam için (Sermaye, doğal kaynaklar, girişim, aktif nüfus ve işgücü) üretim faktörlerinin makro boyutuyla üretim sürecine katılmasından doğan tanımından ziyade, istihdam teriminin emek-yoğun, iş gücü an- 
lamları üzerinden değerlendirilecektir. Bu nedenle dar anlamda istihdam, emeğin üretime katılması demektir. Bir ülkede 14-65 yaşları arasında bulunanlar aktif nüfusu oluşturur ve bu ekonominin işgücü/emek potansiyelini ifade etmektedir. Diğer bir ifadeyle aktif nüfus içinde çalışma istek ve yeteneğinde olup yürürlükteki ücret haddi ve çalışma koşullarında üretim faaliyetlerine emekleriyle katılmak isteyenleri ifade eder (Erdoğan, 1995, s.227).

Turizmin temel ekonomik önemi, bir ülke veya bölgeyi ziyaret eden turistler tarafından yapılan harcamalardır. Turizmin ülkelere veya uluslararası asal ekonomik değeri, turistlerin ziyaret ettikleri yerlerde yaptıkları harcamalar yoluyla, ülkeye veya o bölgede yaşayan yerel halka ekonomik artı değer kazandırmasıdır. Her sene turizmin küresel hareketi yoluyla gelişmiş ülke ekonomilerden diğer ülke ekonomilere ciddi miktarlarda maddi ve manevi değer aktarımı yapılmaktadır (Zengin, 2010, s.104). Ayrica, turizm faaliyetleri sayesinde yerel ekonomi önemli düzeyde gelişerek büyümekte ve yerelde yaşayanlara çeşitli istihdam olanakları sağlamaktadır. Bu bakımdan yerel yöneticiler tarafından bütüncül bir şekilde yereldeki turizmin gelişmesine yönelik çaba göstermeleri gerekmektedir.

\section{Turizmin Yerel Kalkınmadaki Önemi Van Örneğinde Yapılan Alan Araştırmasında Elde Edilen Bulgular}

Bu kısımda; çalışmada örneklem olarak alınan Van kenti hakkında genel sosyo-ekonomik bilgilerin verilmesinin yanında; araştırmanın amacı, evreni ve örneklemi, sınırlılıkları veri toplama tekniğinden bahsedilerek verilerin analizinde kullanılan yöntemler üzerinde durulmuştur.

\section{Alan Araştırması Kapsamında Yer Alan Van Kentinin Sosyo- Ekonomik Durumu}

Gelişmekte olan veya geri kalmış bölgelerin sosyo-ekonomik gelişimi açısından turizm önemli imkanlar sunduğu bilinmektedir. Türkiye'nin geri kalmış illerinden biri olan Van kentinin ekonomik ve sosyal gelişiminde bugüne kadar tarım ve hayvancıllk sektörü egemen olmuştur. Tarım ve hayvancllık faaliyetlerine turizm sektörünün de 
eklenmesinin bölgenin kalkınması için önemli bir fırsat olarak görülmektedir. Bu fırsatı doğuran yegane faktörün coğrafi ve kültürel yakınlığı ile Van kentinde turizm hareketinin önemli hedef kitlesini İranlı ziyaretçiler oluşturmaktadır.

Van kentinin ülke ekonomisindeki konumu ve gelişmişlik düzeyine ilişkin yapılan durum tespitinde ülkenin 75 . kenti konumunda olduğu görülmektedir. Kalkınmada öncelikli yöreler arasında bulunmasına rağmen Van kenti istenilen ekonomik gelişmeleri bir türlü gösterememektedir. Yerel ekonomik kalkınma sürecinin başarıyla sürdürülebilir kılınması açısından sosyo-ekonomik ve sosyo-kültürel yapının analiz edilmesi ve çıkan bulgular rehberliğinde gerekli idari, mali, siyasi ve ekonomik teşviklerle desteklenmesi önem arz etmektedir.

\section{Araştırmanın Metodolojisi}

Çalışmanın bu bölümünde gerçekleştirilen araştırma süresi ile ilgili bilgiler verilmiştir. Araştırmanın hangi amaçla yapıldığı, öneminin ne olduğu, hangi yöntem ve metotların kullanıldığı, araştırmanın evreni ve örneklemini hangi grupların oluşturduğu, veri toplama araçlarını, veri toplama süreçlerini, araştırmada hangi kısıtlıkların olduğunu, hangi ölçeğin kullanıldığı gibi konulara yer verilmiştir. Elde edilen veriler ışığında araştırma bulgularının sonuçları, tablolar yardımıyla aktarılmaya çalışılmıştır.

\section{Araştırmanın Amacı, Önemi ve Kapsamı}

Bu çalışmanın temel amacı, Van ilini ziyaret eden İranlı turistlerin kent ekonomisine sağladıkları girdi-çıktıları ölçmek, yerel ekonomik kalkınma ile turizm arasındaki ilişkiyi ortaya çıkarmaktır. Bu temel esas üzerinden çalışma, yerel ekonominin kalkınmasında ve dönüşümünde turizm sektörünün önemini ortaya koymaya yönelik bir çerçeve çizmeyi amaçlamaktadır.

Çalışmanın kapsamı 2 aşamadan oluşmaktadır. Birincisi, Van İline gelen İranlı turistlerle ilgili olarak sahadaki verilen toplanması, elde edilen verilerin analizinin yapılmasıdır. Yine bu aşamada Van'a gelen İranlı ziyaretçilerin, geliş koşullarını, nedenlerini, kalma sürelerini, ko- 
naklama biçimlerini, harcama miktarını, geliş sıklıklarını ve tercihlerinin belirlenmesi ve taşıdıkları demografik özelliklerinin tespit edilerek, çıkarılan turist profiline göre yorumlamalar yapılmıştır. Çalışmada toplanan verilerin analiz edilmesi sonrasında Van'ın İranlı turistlerin algısındaki yeri tanımlanmakta ve daha sonraki süreçte devamlı gelişleri sağlamak için ortaya konulması gereken proje ve stratejiler geliştirerek Van ilinin turistik bir destinasyon bölgesi olduğu imajına katkı sunulmaya çalışılmıştır.

İkincisi ise kentin ekonomisinin ana öğesi konumundaki hizmet sektörünün turizmden beklentileri, hangi sorunlar ile karşılaştıkları ve ekonomik değer olarak turizmin hizmet sektörü üzerindeki etkilerinin ölçülmesi konularına yer verilmiştir.

\section{Araştırmanın Yöntemi, Evreni, Örneklemi ve Sınırlılıkları}

Çalışmada yöntem olarak anket tekniğinden faydalanılmış olup, anket, Van kentinde bulunan ve basit tesadüfi örneklem yöntemi ile seçilen 300 İranlı turist ile yapılmıştır. Öncelikle Türkçe olarak hazırlanan soru formu daha sonra Türkçe-Farsça dillerine hakim uzman kişiler tarafından kontrol edilerek gerekli düzenlemeler yapılmıştır.

İranlı turistlere yönelik gerçekleştirilen ziyaretçi anketi ölçeğinin temelini Uğurlar (2006)'ın Van ilini ziyaret eden tüm yabancı turistlere uyguladığı çalışma oluşturmaktadır. Bununla birlikte ilgili literatür taranmış (Bahar 2007; Yıldız, 2007) ve anket sorularına son şekli verilmiştir.

Hazırlanan anket formu 3 aşama ve 15 sorudan oluşturulmuştur. İranlı turistlere uygulanan ilk aşama turist profilini belirlemeye yönelik ilk 6 sorudan oluşmaktadır. İkinci aşama ziyaretçilerin harcama, tüketim ve tercihlerini saptamaya yönelik 8 sorudan oluşmaktadır. Böylelikle ziyaretçilerin Van kentini tercih etme sebeplerini, kalış sürelerini, harcama miktarları, gezdikleri yerler belirlenerek uygun mal ve hizmetlerin sağlanmasına yönelik çalışılmıştır. Son aşamada turistlerin yapmış oldukları ziyaretle ilgili memnuniyetlerine yönelik 1 soru yer almaktadır.

Araştırmanın örneklemi ulaşım ve maliyet gerekçeleri ile Van kentinde bulunan İranlı turistler özelinde yapılarak diğer yabancı ve yerli turistler kapsam dışında tutularak sınırlandırılmıştır. 


\section{Araştırmanın Bulguları}

Tablo 1. Katılımcıların Demografik ve Sosyo-Ekonomik Özelliklerinin Dağılımı

\begin{tabular}{|c|c|c|c|}
\hline \multicolumn{2}{|c|}{ Değişkenler } & Frekans $(\mathrm{F})$ & Yüzde (\%) \\
\hline \multirow[t]{2}{*}{ Cinsiyet } & Kadın & 138 & 46,0 \\
\hline & Erkek & 162 & 54,0 \\
\hline \multirow{5}{*}{ Yaş } & $1-20$ & 10 & 3,3 \\
\hline & $21-30$ & 85 & 28,4 \\
\hline & $31-40$ & 127 & 42,3 \\
\hline & $41-50$ & 41 & 13,7 \\
\hline & 51 ve Üzeri & 37 & 12,3 \\
\hline \multirow{3}{*}{ Öğrenim Durumu } & İlköğretim & 10 & 3,3 \\
\hline & Lise & 42 & 14,0 \\
\hline & Üniversite & 248 & 82,7 \\
\hline \multirow{5}{*}{ Meslek Durumu } & Kamu Sektörü & 52 & 17,3 \\
\hline & Özel Sektör & 93 & 31,0 \\
\hline & Ticari İşletme & 63 & 21,0 \\
\hline & Öğrenci & 35 & 11,7 \\
\hline & Diğer & 57 & 19,0 \\
\hline \multirow[t]{5}{*}{ Gelir Durumu } & $1-250 \$$ & 94 & 31,3 \\
\hline & $251-500 \$$ & 117 & 39,0 \\
\hline & $501-1000 \$$ & 54 & 18,0 \\
\hline & 1001 ve Üzeri Dolar & 15 & 5,0 \\
\hline & $\begin{array}{l}\text { Gelir Durumunu } \\
\text { Belirtmeyenler }\end{array}$ & 20 & 6,7 \\
\hline
\end{tabular}

Tablo 1 incelendiğinde; ankete katılan turistlerin 138'i kadınlardan, 162'si ise erkek turistlerden oluşmaktadır. Katılımcılardan 10 kişi 1-20 yaş grubunu, 85 kişi 21-30 yaş, 127 kişi 31-40 yaş, 41 kişi $41-50$ yaş ve 37 kişi de 51 ve üzeri yaş gurubunu oluşturmaktadır. Yaş guruplarının ankete katılımı incelendiğinde, Van kentini ziyaret eden turist tipinin ağırlıklı olarak 212 kişi $\% 70,7$ oranıla 21-40, orta yaş gurubunu kapsadığ1 görülmektedir. Katılımcıların öğrenim durumlarına bakıldığında; 10 kişi ilköğretim, 42 kişi lise, 65 kişi ön lisans, 118 kişi lisans ve 65 kişi lisansüstü mezunudur. Katılımcıların meslek gruplarına bakıldığında; 52 kişinin kamu görevlisi, 93 kişinin özel sektörde, 63 kişinin ticari işletmelerde, 6 kişinin tarım ve hayvancılıkta, 26 kişinin işsiz, 35 kişinin öğrenci, 18 kişinin ev hanımı olduğu görülmektedir. 
Bunun yanında emekli, çalışmayan vb. nedenlerle de 7 kişinin diğer seçeneğini işaretlediği görülmektedir. Van kentini ziyaret eden İranlı turistlerin önemli bir kısmının esnaf/tüccar veya özel bir ticari işletmede çalıştığ 1 görülmektedir. Katılımcıların son olarak gelir durumlarına bakıldığında; 94 kişi 1-250 \$, 117 kişi 251-500 \$, 54 kişi 501 - 1000 \$, 15 kişi 1000 ve üzeri \$ aylık geliri olduğunu, 20 kişi ise aylık gelirlerinin ne kadar olduğunu çeşitli gerekçelerle açılamak istememiştir. Katılımcıların çoğunluğunun gelirinin 251-500 \$ arasında olduğu görülmektedir.

Tablo 2. Katılımcıların Seyahatlerinde Kullandı̆̆ı Ulaşım Türlerine Göre Dağılımı

\begin{tabular}{ccc}
\hline Ulaşım Türü & Frekans & Yüzde (\%) \\
\hline Özel Araç & 102 & 34,0 \\
\hline Minibüs / Otobüs & 138 & 46,0 \\
\hline Tren & 14 & 4,7 \\
\hline Uçak & 46 & 15,3 \\
\hline Toplam & 300 & 100,00 \\
\hline
\end{tabular}

Tablo 2'de ankete katılan turistlerin seyahatlerini, hangi ulaşım türünü kullanarak yaptıklarına dair bilgiler verilmektedir. Anket çalışmasına katılan turistlerden 102 kişi özel araçla, 138 kişi minibüs veya otobüs ile 14 kişi trenle ve 46 kişi uçak kullanarak Van kentine seyahat ettiği bilgisini açıklamıştır. Van kentinin coğrafi olarak İran'a komşu olması sebebiyle ankete katılanların önemli bir bölümü ziyaretlerini bireysel araçlarıyla yapabilme olanağına sahip oldukları ön plana çıkmaktadır. Yine tabloda katılımcıların büyük çoğunluğunun toplu taşıma araçları ile seyahatlerini gerçekleştirdikleri görülmektedir.

Tablo 3. Katılımcıların Konaklama Gün Sayısına Göre Dă̆ılımı

\begin{tabular}{lcc}
\hline Konaklama Gün Sayıs1 & Frekans Dağılımı & Yüzde (\%) \\
\hline Günübirlik & 6 & 2,0 \\
\hline 2-3 gün & 171 & 57,0 \\
\hline 4-6 gün & 106 & 35,3 \\
\hline 7 gün ve üzeri & 17 & 5,7 \\
\hline Toplam & 300 & 100,00 \\
\hline
\end{tabular}


Tablo 3'de Van kentini ziyaret eden İranlı turistlerin kentte kaç gün konaklama yaptıklarına dair verileri göstermektedir. Buna göre katılımcllardan 6 kişi Van'ı günübirlik ziyaret ederken, 171 kişi 2-3 gün, 106 kişi 4-6 gün ve 17 kişi 7 gün ve üzeri seyahatlerini gerçekleştirdiklerini belirtmişlerdir. Yukarıdaki bilgiler ışığında ve ziyaretçilerle seyahatleri hakkında yapılan görüşmelerde Van kentini ziyaret etme sürelerinin genellikle 1-3 gün arası gerçekleştiği görülmektedir. Kenti ziyaret eden turistlerin önemli bir kısmının seyahatlerini paket tur ile gerçekleştirdiği, turların süresinin genellikle hafta sonunu kapsadığı belirtilmektedir. 4 gün ve üzerini kapsayan tatil sürelerinin genellikle İranlıların bahar dönemlerine denk gelen Nevruz bayramlarını ve yaz tatili süreçlerinde değerlendirildiği yine yapılan görüşmelerden ortaya çıkan bulgulardandır.

Tablo 4. Katılımcıların Doğal Çevrenin Durumuna Yönelik Görüşlerine İlişkin Dă̆ılımı

\begin{tabular}{lcc}
\hline $\begin{array}{l}\text { Doğal Çevrenin Duru- } \\
\text { munu Beğendim }\end{array}$ & Frekans & Yüzde (\%) \\
\hline Kesinlikle Katıliyorum & 44 & 14,7 \\
\hline Katılıyorum & 115 & 38,3 \\
\hline Orta Düzeyde Katılıyorum & 109 & 36,3 \\
\hline Katılmıyorum & 21 & 7,0 \\
\hline Kesinlikle Katılmiyorum & 11 & 3,7 \\
\hline Toplam & 300 & 100,0 \\
\hline
\end{tabular}

Tablo 4'de ankete katılan İranlı turistlerin doğal çevrenin durumundan memnuniyetlerine dair görüşlerin yansitılmaktadır. Ankete katılan örneklem grubundan 44 katılımcı kesinlikle katıllyorum, 115 katılımcı katılıyorum, 109 katılımcı orta düzeyde katılıyorum, 21 katılımcı katılmıyorum, 11 katılımcı ise kesinlikle katılmıyorum şeklinde görüş bildirmiştir. Genel olarak tablo yorumlandığında katılımcıların kentteki doğal çevreyi beğendiği söylenebilir.

İranlı turistlerin Van kentini tatil için seçme nedenlerine ilişkin tercihlerini gösterir tablo 5 incelendiğinde; 45 kişinin sosyal, tarihi ve sosyal güzelliklerden dolayı, 103 kişinin gezmek eğlenmek ve alışveriş için, 5 kişinin arkadaş veya akraba ziyareti, 6 kişinin iş nedeniyle, 3 kişinin sağlık, 54 kişinin tatil maliyetlerinin ucuzluğu, 76 kişinin yakınlık ve 
ulaşım kolaylığı nedeniyle, 8 kişinin ise diğer seçeneklerden dolayı Van kentini tercih ettiği görülmektedir.

Tablo 5. Katılımcıların Van Kentini Tercih Etme Sebeplerine Göre Dağılımı

\begin{tabular}{lcc}
\hline \multicolumn{1}{c}{ Tercih Sebepleri } & Frekans & Yüzde (\%) \\
\hline Sosyal tarihi ve kültürel güzellikler & 45 & 15,0 \\
\hline Gezmek, eğlenmek ve Alışveriş & 103 & 34,3 \\
\hline Arkadaş ve akraba ziyareti & 5 & 1,7 \\
\hline İş & 6 & 2 \\
\hline Sağllk & 3 & 1 \\
\hline Tatilin maliyeti & 54 & 18 \\
\hline Yakınlık ve ulaşım kolaylığı & 76 & 25,3 \\
\hline Diğer & 8 & 2,7 \\
\hline Toplam & 300 & 100,00 \\
\hline
\end{tabular}

Van kentini ziyaret eden İranlı turistlerin önemli bir çoğunluğunun gezmek, eğlenmek ve alışveriş yapmayı tercih ettikleri anlaşılmaktadır. Bununla birlikte belirtilen farklı sebeplerden dolayı İranlı turistlerin Van kentine seyahat ettikleri görülmektedir. Diğer seçeneği tercih eden turistlerin bavul turizmi, kısa süreli eğitim ve tatil ve kongre turizmine katılmak amacıyla kente seyahat ettikleri görüşmeler sonrasında ulaşılan bulgulardandir.

Tablo 6. Katılımcıların Toplam Harcama Miktarına Göre Dağılımı

\begin{tabular}{lcc}
\hline Toplam Harcama & Frekans & Yüzde $(\%)$ \\
\hline $1-250 \$$ & 54 & 18,0 \\
\hline $251-500 \$$ & 121 & 40,3 \\
\hline $501-1000$ \$ & 100 & 33,3 \\
\hline 1001 \$ ve üzeri & 25 & 8,4 \\
\hline Toplam & 300 & 100,00 \\
\hline
\end{tabular}

Van kentini ziyaret eden İranlı turistlerin ziyaretleri süresince yapacakları tatil için ayırdıkları toplam harcama bütçesinin dağılımını gösterir tablo 6 incelendiğinde; 54 kişinin $1-250$ \$, 121 kişinin 251-500 \$, 100 kişinin 501-1000 \$ ve 25 kişinin de 1001 \$ ve üzeri tatil için bütçe ayırdığı belirtilmektedir. Turistlerin büyük çoğunluğunun $251-1000$ \$ arası tatil için bütçe ayırdıkları görülmektedir. 
Tablo 7. Katılımcıların Van Kenti Deneyimlerine İlişkin Dă̆ılımı

\begin{tabular}{lcc}
\hline $\begin{array}{l}\text { Van Kentindeki Deneyimlerim- } \\
\text { den Hoşlandım }\end{array}$ & Frekans Dağılımı & Yüzde Değeri (\%) \\
\hline Kesinlikle Katılıyorum & 85 & 28,3 \\
\hline Katılıyorum & 150 & 50,0 \\
\hline Orta Düzeyde Katılıyorum & 46 & 15,4 \\
\hline Katılmıyorum & 15 & 5,0 \\
\hline Kesinlikle Katılmıyorum & 4 & 1,3 \\
\hline Toplam & 300 & 100,0 \\
\hline
\end{tabular}

Tablo 7'de ankete katılan İranlı turistlerin Van'da geçirdikleri süre boyunca deneyimlerinden hoşlanıp-hoşlanmadıklarına dair görüşleri yansıtılmıştır. Çalışmada belirlenen örneklem grubundan 85 katılımcı kesinlikle katılıyorum, katılımcıların yarısı 150 katılımcı katılıyorum, 46 katılımcı orta düzeyde katılıyorum, 15 katılımcı katılmıyorum ve 4 katılımcı kesinlikle katılmıyorum şeklinde görüş bildirmiştir. Tablo'da görüldüğü üzere ankete katılan İranlı turistlerin büyük bir çoğunluğunun Van kentindeki deneyimlerinden hoşlandıkları ve kentten memnun kaldıkları anlaşılmaktadır.

Tablo 81. Katılımcıların Cinsiyet Durumu ile Gelirlerinin Karşılaştırılmasına İlişkin Ki- Kare Testi Analiz Sonuçları $(n=300)$

\begin{tabular}{|c|c|c|c|c|c|}
\hline \multirow{2}{*}{\multicolumn{3}{|c|}{ Değişkenler }} & \multicolumn{3}{|c|}{ Cinsiyetiniz } \\
\hline & & & Kadın & Erkek & Toplam \\
\hline \multirow{8}{*}{$\begin{array}{l}\text { Gelir Duru- } \\
\text { mununuz? }\end{array}$} & \multirow{2}{*}{ 1-250 Dolar } & $\mathrm{F}$ & 55 & 39 & 94 \\
\hline & & $\%$ & 45,8 & 24,4 & 33,6 \\
\hline & \multirow{2}{*}{ 251-500 Dolar } & $\mathrm{F}$ & 50 & 67 & 117 \\
\hline & & $\%$ & 41,7 & 41.9 & 41,8 \\
\hline & \multirow{2}{*}{ 501-1000 Dolar } & $\mathrm{F}$ & 12 & 42 & 54 \\
\hline & & $\%$ & 10,0 & 26,3 & 19,3 \\
\hline & \multirow{2}{*}{$\begin{array}{c}\text { 1001- Üzeri } \\
\text { Dolar }\end{array}$} & $\mathrm{F}$ & 3 & 12 & 15 \\
\hline & & $\%$ & 2,5 & 7,5 & 5,4 \\
\hline \multicolumn{6}{|c|}{$X^{2}=21,995$} \\
\hline
\end{tabular}

${ }^{*} P<0,01$

Tablo 8'de katılımcların cinsiyet durumu ile gelir durumlarının karşılaştırılmasına ilişkin ki-kare testi analiz sonuçlarına bakıldığında; cinsiyeti kadın olan 55 katılımcinın $(\% 45,8)$ 1-250 Dolar arasında geliri 
bulunurken, 50 katılımcinın (\%41,7) 251-500 Dolar, 12 katılımcinın (\%10,0) 501-1000 Dolar ve 3 katılımcının (\%2,5) 1001 Dolar üzerinde geliri olduğu; cinsiyeti erkek olan 39 katılımcının (\%24,4) 1-250 Dolar, 67 katilımcinın (\%41,9) 251-500 Dolar, 42 katilımcinın (\%26,3) 501-1000 Dolar ve 12 katılımcının $(\% 7,5) 1001$ Dolar ve üzeri gelire sahip oldukları görülmektedir.

Tabloda $p$ değerine bakıldığında; $p$ değerinin 0,000 olduğu ve $p<0,05$ olduğundan aralarında anlamlı bir ilişki bulunduğu görülmektedir. Bu doğrultuda kadınların gelir düzeyinin erkeklere göre daha düşük olduğu söylenebilir.

Tablo 92. Katılımcıların Meslek Grupları ile Gelir Durumlarının Karşılaştırılmasına İlişkin Ki-Kare Testi Analiz Sonuçları $(n=300)$

\begin{tabular}{|c|c|c|c|c|c|c|c|}
\hline \multicolumn{3}{|c|}{ Değişkenler } & \multicolumn{5}{|c|}{ Gelir Durumunuz? } \\
\hline & & & $1-250$ & $251-500$ & $501-1000$ & 1001- Üzeri & Toplam \\
\hline \multirow{20}{*}{ Mesleğiniz? } & \multirow{3}{*}{$\begin{array}{c}\text { Kamu } \\
\text { Sektörü }\end{array}$} & & & & & & \\
\hline & & $\mathrm{F}$ & 9 & 29 & 11 & 0 & 49 \\
\hline & & $\%$ & 18,4 & 59,2 & 22,4 & 0,0 & 100,0 \\
\hline & \multirow[t]{2}{*}{ Özel Sektör } & $\mathrm{F}$ & 18 & 44 & 20 & 9 & 91 \\
\hline & & $\%$ & 19,8 & 48,4 & 22,0 & 9,9 & 100,0 \\
\hline & \multirow{2}{*}{$\begin{array}{c}\text { Ticari İşlet- } \\
\text { me }\end{array}$} & $\mathrm{F}$ & 10 & 26 & 22 & 3 & 61 \\
\hline & & $\%$ & 16,4 & 42,6 & 36,1 & 4,9 & 100,0 \\
\hline & \multirow{2}{*}{$\begin{array}{c}\text { Tarım ve } \\
\text { Hayvancılık }\end{array}$} & $\mathrm{F}$ & 2 & 3 & 1 & 0 & 6 \\
\hline & & $\%$ & 33,3 & 50,0 & 16,7 & 0,0 & 100,0 \\
\hline & \multirow[t]{2}{*}{ İşsiz } & $\mathrm{F}$ & 14 & 2 & 0 & 1 & 17 \\
\hline & & $\%$ & 82,4 & 11,8 & 0,0 & 5,9 & 100,0 \\
\hline & \multirow[t]{2}{*}{ Öğrenci } & $\mathrm{F}$ & 25 & 7 & 0 & 1 & 33 \\
\hline & & $\%$ & 75,8 & 21,2 & 0,0 & 3,0 & 100,0 \\
\hline & \multirow[t]{2}{*}{ Ev Hanımı } & $\mathrm{F}$ & 12 & 4 & 0 & 0 & 16 \\
\hline & & $\%$ & 75,0 & 25,0 & 0,0 & 0,0 & 100,0 \\
\hline & \multirow[t]{2}{*}{ Diğer } & $\mathrm{F}$ & 4 & 2 & 0 & 1 & 7 \\
\hline & & $\%$ & 57,1 & 28,6 & 0,0 & 14,3 & 100,0 \\
\hline & \multirow[t]{2}{*}{ Toplam } & $\mathrm{F}$ & 94 & 117 & 54 & 15 & 280 \\
\hline & & $\%$ & 33,6 & 41,8 & 19,3 & 5,4 & 100,0 \\
\hline & & & $X^{2}=98,0$ & $\mathrm{p}=0,000$ & & & \\
\hline
\end{tabular}

Tablo 9'da katılımciların meslek grupları ile gelir durumlarının karşılaştırılmasına ilişkin ki-kare testi analiz sonuçlarına bakıldığında; 
kamu sektöründe çalışan katılımclardan 9 kişi 1-250 Dolar, 29 kişi 251500 Dolar, 11 kişi 501-1000 Dolar iken 1000 Dolar ve üzeri gelire sahip kamu çalışanı bulunmamaktayken, özel sektörde çalışan katılımcılardan 18 kişi 1-250 Dolar, 44 kişi 251-500 Dolar, 20 kişi 501-1000 Dolar ve 9 kişi 1000 Dolar ve üzeri gelire sahip olduğu, ticari işletme sahibi olan katılımclardan 10 kişi 1-250 Dolar, 26 kişi 251-500 Dolar, 22 kişi 501-1000 Dolar ve 3 kişi 1000 Dolar ve üzeri gelire sahip olduğu, tarım ve hayvancılık sektöründe çalışan katılımcılardan 2 kişi 1-250 Dolar, 3 kişi 251-500 Dolar ve 1 kişi 501-1000 Dolar arası gelire sahip olduğu, halen işsiz olduğunu beyan eden katılımcılardan 14 kişi 1-250 Dolar, 2 kişi 251500 Dolar ve 1 kişi 1000 Dolar ve üzeri gelire sahip olduğunu, öğrenci olduğunu açıklayan katılımcılardan 25 kişi 1-250 Dolar, 7 kişi 251-500 Dolar ve 1 kişi 1000 Dolar ve üzeri gelire sahip olduğu, ev hanımı olduğunu ifade eden katılımcılardan 12 kişi 1-250 Dolar, 4 kişi 251-500 Dolar geliri olduğu, diğer meslek gruplarında yer alan 4 kişinin 1-250 Dolar, 2 kişinin 251-500 Dolar, 1 kişinin ise 1000 Dolar ve üzeri gelire sahip olduğunu belirtmiştir. Toplam katılımcılardan 94 kişinin $(\% 33,6) 1$ 250 Dolar, 117 kişinin (\%41,8) 251-500 Dolar, 54 kişinin (\%19,3) 501-1000 Dolar ve 15 kişinin $(\% 5,4) 1000$ Dolar ve üzeri gelire sahip olduğu görülmektedir.

Tabloda $p$ değerine bakıldığında; $p$ değerinin 0,000 olduğu ve $p<0,05$ olduğundan aralarında anlamlı bir ilişki bulunmaktadır. Ticari işletme sahibi, özel sektör çalışanı ve kamu sektörü çalışanı olan katılımcıların diğer meslek gruplarına göre daha yüksek gelir seviyesine sahip olduğu söylenebilir.

Tablo $10^{\prime}$ da yer alan katılımciların Van kentini tercih etme nedenleri ile kalış sürelerinin karşılaştırılmasına ilişkin ki-kare testi analiz sonuçlarına bakıldığında; sosyal tarihi ve kültürel güzellikler nedeniyle gelen katılımclardan 23'ünün $(\% 13,5)$ 2-3 gün kaldığı, 18 kişinin $(\% 17,0)$ 4-6 gün, 4 kişinin $(\% 23,5) 7$ gün ve üzeri kaldığı, gezmek eğlenmek ve alışveriş yapmak nedeniyle Van kentini tercih eden katılımclardan 1 kişinin (\%16,7) günübirlik kaldığ 1 , 32 kişinin (\%18,7) 2-3 gün, 26 kişinin $(\% 24,5)$ 4-6 gün ve 5 kişinin $(\% 29,4) 7$ gün ve üzeri kaldığ 1 görüülmektedir. 
Tablo 103. Katılımcıların Van Kentini Tercih Etme Nedenleri ile Kalış Sürelerinin Karşılaştırılmasına İlişkin Ki- Kare Testi Analiz Sonuçları (n=300)

\begin{tabular}{|c|c|c|c|c|c|c|}
\hline \multicolumn{3}{|c|}{ Değişkenler } & \multicolumn{4}{|c|}{$\begin{array}{c}\text { Van Kentindeki Kalış Süreniz Kaç } \\
\text { Gündür? }\end{array}$} \\
\hline & & & Günübirlik & $\begin{array}{l}2-3 \\
\text { Gün }\end{array}$ & $\begin{array}{l}4-6 \\
\text { Gün }\end{array}$ & $\begin{array}{l}7 \text { Gün ve } \\
\text { Üzeri }\end{array}$ \\
\hline \multirow{18}{*}{$\begin{array}{l}\text { Van İlini } \\
\text { Tercih Etme } \\
\text { Nedeniniz } \\
\text { Nedir? }\end{array}$} & \multirow{2}{*}{$\begin{array}{l}\text { Sosyal Tarihi ve Kültürel } \\
\text { Güzellikler }\end{array}$} & $\mathrm{F}$ & 0 & 23 & 18 & 4 \\
\hline & & $\%$ & 0,0 & 13,5 & 17,0 & 23,5 \\
\hline & \multirow{2}{*}{$\begin{array}{l}\text { Gezmek, Eğlenmek ve } \\
\text { Alışveriş Yapmak }\end{array}$} & $\mathrm{F}$ & 1 & 32 & 26 & 5 \\
\hline & & $\%$ & 16,7 & 18,7 & 24,5 & 29,4 \\
\hline & \multirow{2}{*}{$\begin{array}{l}\text { Arkadaş ve Akraba } \\
\text { Ziyareti }\end{array}$} & $\mathrm{F}$ & 0 & 2 & 3 & 0 \\
\hline & & $\%$ & 0,0 & 1,2 & 2,8 & 0,0 \\
\hline & \multirow[t]{2}{*}{ İş } & $\mathrm{F}$ & 2 & 3 & 1 & 0 \\
\hline & & $\%$ & 33,3 & 1,8 & 0,9 & 0,0 \\
\hline & \multirow[t]{2}{*}{ Sağlık } & $\mathrm{F}$ & 0 & 1 & 2 & 0 \\
\hline & & $\%$ & 0,0 & 0,6 & 1,9 & 0,0 \\
\hline & \multirow[t]{2}{*}{ Tatilin Maliyeti } & $\mathrm{F}$ & 2 & 33 & 16 & 3 \\
\hline & & $\%$ & 33,3 & 19,3 & 15,1 & 17,6 \\
\hline & \multirow{2}{*}{$\begin{array}{l}\text { Yakınlık ve Ulaşım Ko- } \\
\text { laylığı }\end{array}$} & $\mathrm{F}$ & 1 & 49 & 29 & 5 \\
\hline & & $\%$ & 16,7 & 28,7 & 27,4 & 29,4 \\
\hline & \multirow[t]{2}{*}{ Diğer } & $\mathrm{F}$ & 0 & 28 & 11 & 0 \\
\hline & & $\%$ & 0,0 & 16,4 & 10,4 & 0,0 \\
\hline & \multirow[t]{2}{*}{ Toplam } & $\mathrm{F}$ & 6 & 171 & 106 & 17 \\
\hline & & $\%$ & 100,0 & 100,0 & 100,0 & 100,0 \\
\hline \multicolumn{7}{|c|}{$\mathrm{X}^{2}=44,027 \mathrm{p}=0,002^{*}$} \\
\hline
\end{tabular}

${ }^{*} \mathrm{P}<0,01$

Arkadaş ve akraba ziyareti nedeniyle Van'1 tercih eden katılımcılardan 2 kişinin $(\% 1,2)$ 2-3 gün ve 3 kişinin $(\% 2,8)$ 4-6 gün kaldı̆̆ı, iş nedeniyle Van kentini tercih eden katılımclardan 2 kişi $(\% 33,3)$ günübirlik kalırken, 3 kişi $(\% 1,8)$ 2-3 gün ve 1 kişi $(\% 0,9)$ 4-6 gün üzeri kaldı̆̆ı̆, sağlık sorunları nedeniyle Van kentini tercih eden katılımcılardan 1 kişi $(\% 0,6)$ 2-3 gün ve 2 kişinin (\%1,9) 4-6 gün kaldığı, tatilin maliyeti nedeniyle Van kentini tercih eden katılımcılardan 2 kişi $(\% 33,3)$ günübirlik, 33 kişi (\%19,3) 2-3 gün, 16 kişi (\%15-1) 4-6 gün ve 3 kişi $(17,6) 7$ gün ve üzeri kaldığı, yakınlık ve ulaşım kolaylığg nedeniyle Van kentini tercih eden katılımcılardan 1 kişi (\%16,7) günübirlik, 49 kişi (\%28,7) 2-3 gün, 29 kişi $(\% 27,4)$ 4-6 gün ve 5 kişi $(\% 29,4) 7$ gün ve üzeri kaldığı, diğer neden- 
lerden dolayı Van kentini tercih eden katılımcılardan 28 kişinin (\%16,4) 2-3 gün ve 11 kişinin ( 10,4) 4-6 gün süreyle Van kentinde kaldığı belirtilmektedir.

Tabloda $p$ değerine bakıldığında, $p$ değerinin 0,000 olduğu ve $p<0,05$ olduğundan aralarında anlamlı bir ilişki bulunmaktadır. Yakınlık ve ulaşım kolaylığı nedeniyle Van kentini tercih eden katılımcıların 2-3 günlük kısa süreliğine konaklama yaptıkları görülmektedir. Ayıca gezmek, eğlenmek ve alışveriş yapmak için Van kentini tercih eden katılımcıların 1-6 gün aralığında bir haftalık tatil süresince konaklama yaptıkları, diğer nedenlerle yapılan seyahatlerin hem sürelerin kısa olduğu hem de katılımcı sayısı olarak istenilen düzeyde olmadığı söylenebilir.

Tablo 114. Katılimcilarn Gelir Durumlart ile Toplam Harcamalarinın Karşılaştırılmasına İlişkin Ki- Kare Testi Analiz Sonuçlan ( $n=300)$

\begin{tabular}{|c|c|c|c|c|c|c|c|}
\hline \multicolumn{3}{|c|}{ Değişkenler } & \multicolumn{4}{|c|}{ Toplam Yapılan Harcama? } & \multirow[b]{2}{*}{ Toplam } \\
\hline & & & $1-250$ & $251-500$ & $501-1000$ & $1001-$ & \\
\hline \multirow{11}{*}{$\begin{array}{l}\text { Gelir Duru- } \\
\text { munuz? }\end{array}$} & 1250 & $F_{1}$ & 29 & 37 & 26 & $?$ & 94 \\
\hline & Dolar & $\%$ & 30,9 & 39,4 & 27,7 & 2,1 & 100,0 \\
\hline & $251-500$ & $\mathrm{~F}$ & 17 & 53 & 36 & 10 & 80 \\
\hline & Dolar & $\%$ & 14,7 & 45,7 & 31,0 & 8,6 & 100,0 \\
\hline & $501-1000$ & $\mathrm{~F}$ & 5 & 14 & 29 & 7 & 117 \\
\hline & Dolar & $\%$ & 9,3 & 25,9 & 51,9 & 13,0 & 100,0 \\
\hline & 1001- & $\mathrm{F}$ & 0 & 6 & 5 & 4 & 38 \\
\hline & $\begin{array}{l}\text { Üzeri } \\
\text { Dolar }\end{array}$ & $\%$ & 0,0 & 40,0 & 33,3 & 26,7 & 100,0 \\
\hline & Toplam & $\mathrm{F}$ & 51 & 110 & 96 & 23 & 280 \\
\hline & & $\%$ & 18,3 & 39,4 & 34,1 & 8,2 & 100,0 \\
\hline & \multicolumn{7}{|c|}{$X^{2}=36,143 p=0,000^{*}$} \\
\hline
\end{tabular}

${ }^{*} P<0,01$

Tablo 11'de katılımcların gelir durumları ile toplam yapmış oldukları harcamanın karşılaştırılmasına ilişkin ki-kare testi analiz sonuçlarına bakıldığında; gelir düzeyi 1-250 dolar olan katılımclardan 29 kişi (\%30,9) 1-250 Dolar harcama yaparken, 37 kişi $(\% 39,4)$ 251-500 Dolar, 26 kişi $(\% 27,7)$ 501- 1000 Dolar ve 2 kişi $(\% 2,1) 1001$ Dolar ve üzeri harcama 
yaptığı, gelir düzeyi 251-500 Dolar arası olan katılımcılardan 17 kişi (\%14,7) 1-250 Dolar arası harcama yaparken, 53 kişi (\%45,7) 251-500 Dolar, 36 kişi $(\% 31,0)$ 501-1000 Dolar ve 10 kişinin $(\% 8,6) 1001$ Dolar ve üzeri harcama yaptığı, gelir düzeyi 501-1000 Dolar arasında olan katılımcılardan 5 kişi $(\% 9,3)$ 1-250 Dolar arası harcama yaparken, 14 kişi (\%25,9) 251-500 Dolar, 29 kişinin (\%51,9) 501-1000 Dolar arası ve 7 kişinin $(\% 13,0) 1001$ Dolar ve üzeri harcama yaptığı, geliri 1001 Dolar ve üzeri olan katılımcılardan 6 kişi $(\% 40,0)$ 251-500 Dolar arası harcama yaparken, 5 kişi $(\% 33,3)$ 501-1000 Dolar arası ve 4 kişi (\%26,7) 1001 Dolar ve üzeri harcama yaptığı görülmektedir. Toplam katılımclardan 51 kişi (\%18,3) 1-250 Dolar arası harcama yaparken, 110 kişi (\%39,4) 251-500 Dolar, 96 kişi (\%34,1) 501-1000 Dolar ve 23 kişi (\%8,) 10001 Dolar ve üzeri toplam harcama yaptıkları belirtilmiştir.

Tabloda $p$ değerine bakıldığında, $p$ değerinin 0,000 olduğu ve $p<0,05$ olduğundan aralarında anlamlı bir ilişki bulunmaktadır. Gelir seviyesi yükseldikçe yapılan toplam harcamanın da aynı düzeyde yükseldiği söylenebilir. Katılımcıların önemli bir çoğunluğunun 251-1000 Dolar arasında toplam harcama yaptıkları görülmektedir.

\section{Sonuç ve Öneriler}

Sürdürülebilir bir turizm hareketinin işlevsel olmasının temelinde, bir ülkedeki turizm faaliyetlerine katılan yerel ve merkezi yönetim ile diğer paydaşların ülke ekonomisine fayda sağlayacak biçimde koordinasyonu, eş güdümlü ortak payda ve yarar ekseninde çalışmalarına bağlıdır. Zira turizm özellikle geri kalmış ya da sanayi ve tarım sektörleri yatırımına uygun olmayan kentlerde turizm sektörü önemli bir yatırım aracı olup, söz konusu kentlerde ekonomik ve sosyal kalkınmanın ana unsuru haline gelebilmektedir. Bu tür kentlere gösterilebilecek örneklerden birisi de Van kentidir.

Yapılan araştırma sonucunda; İranlı turistlerin Van kentinin ülkelerine yakın ve ulaşım kolaylığının olması, kendi ülkeleriyle kıyaslandığında çeşitli özgürlük alanlarına sahip olması, turistik tüketime konu olan mal ve hizmetleri ülkelerinde bulmakta güçlük çekmeleri ve özellikle mevcut rejimin baskısindan bir nebze de olsa kurtulmak, istedikleri gibi giyinmek, rahat bir şekilde dolaşmak, alışveriş yapmak ve eğlenmek 
üzere Van kentini tercih ettikleri, çoğunlukla aileleri ile ve özel arabalarıyla gelen turistler bir haftadan daha az kaldığı, kentin eğlence mekânlarını ve AVM'lerini daha çok dolaştıkları, kenti ziyaret eden İran11 turistlerin tatil süreleri boyunca $250-1000 \$$ arasında ortalama harcama yaptıkları, Turistlerin konaklama sürelerinin 2-3 günle sınırlı olmasından dolayı harcamalarının az olduğu, kentte bulunmaktan turistlerin memnun olduğu ve arkadaşlarına tavsiye edecekleri, ayrıca İranlı turistlerin $\% 39^{\prime}$ u gürültüden, \%30'u kamusal alanlarda çöpten ve kirlilikten, $\% 49^{\prime}$ u kent merkezindeki yoğun yapılaşmadan ve esnaf ve turizm işletmelerin bazı ürünleri fahiş fiyatlarda satmalarından rahatsız oldukları çalışmada elde edilen bulgulardir.

Van kentinin kültürel mirası, tarihi ve doğal güzellikleri, alternatif turizm potansiyeli ve turistik değerler bakımından bir destinasyon merkezi konumunda bulunduğu, mevcut potansiyel değerlendirildiği takdirde turizmin daha da gelişebileceğini göstermesi açısından önemlidir. Türkiye'de son dönemlere kadar önemli oranda turizm hareketlerine eğilim, kıyı kesimlerinde, deniz, kum ve güneş ekseninde değerlendirilmekteydi. $\mathrm{Bu}$ eğilimin neticesinde önemli derece turistik yatırımlarda yine bu kentlerde yoğunlaşmıştır. Turizm ve turist algısının son yıllarda giderek değişmeye başlamasıyla birlikte turizm hareketine yaz mevsimine indirgeyen deniz, kum, güneş ekseninden kopararak alternatif turizm arayışları ön plana çıkmaya başlamıştır. Van kenti sahip olduğu turizm potansiyeli ve alternatif turizm kaynakları bakımından önemli bir destinasyon olarak görülmektedir. Bu nedenle, kalkınmada öncelikli yöreler arasında bulunan Van kenti gibi az gelişmiş olan, fakat turizm potansiyeli bakımından güçlü ve gelişme gösterebilecek fırsatlara sahip yörelerde ulusal ölçekte yatırımların yapılması gerekmektedir. Yıllardır yerel kalkınmada öncelikli iller arasında yer alan Van kentine yönelik turizm yatırımların teşvik edilmesi, mali yardım programlarının devreye konulması gerekmektedir. Ayrıca seyahat acenteleri, konaklama ve ulaşım hizmetleri ve turistlere yönelik yönelik mal ve hizmet üreten ticari işletmeler, turizmin gelişimini tetikleyen en önemli turizm organizasyonlarıdır. Bu organizasyonların ve etkinlerin başarısı, turistik destinasyon bölgesinde turizm gelirlerinde artışlar meydana getirir. $\mathrm{Bu}$ bağlamda, bir yörede turizmin başarı faktörleri bu işletmelere dönük yatırım ve çeşitli teşviklerin yerel ve merkezi yönetimin destekleyici 
politikaları yoluyla gerçekleştirilmektedir. İşletmeler arasında eşgüdüm ve koordinasyonu sağlayacak yasal düzenlemeler, yatırım olanaklarını artıracak ucuz ve uzun vadeli krediler sunmak, gerekli alt ve üstyap1 olanaklarını geliştirerek kentin turizm yoluyla kalkınmasının özendirilmesi, turistlerin rutin aktiviteleri ve alternatif turizm çeşitlerine yönelik atraksiyonlara katılması için gerekli çalışmaların ve düzenlemelerin yapılması gerekmektedir.

Sonuç olarak, Van kentinde yerel yönetimlerin turizm faaliyetlerine yönelik çalışmaları yeterli değildir. Bu bağlamda, yerel ve merkezi yönetim işbirliğiyle; yukarıda belirtilen önerilerin yanında Van kentinde turizminin gelişebilmesi ve hak ettiği yeri alabilmesi için turistlerin dile getirdiği sorunların çözülmesi, beklentilerin karşılanması, turistlerin konaklama gün sayılarının artırılmasına yönelik faaliyetlerin gerçekleştirilmesiyle, Van kentindeki turizmin gelişeceği ve yerelin kalkınmasına önemli katkının sağlanacağı düşünülmektedir. 


\section{EXTENDED ABSTRACT}

\section{Evaluation of The Importance of Tourism in Local Development: The Case of Van City \\ Vedat Yılmaz - Mazlum Karaağaç \\ Van Yüzüncü Yal University}

As in the developed world and the developing countries are also localregional disparities in Turkey. With local economic development policies, socio-economic imbalances in backward areas can be eliminated. Determining the sector where the local resources will be used most effectively reveals the importance of sector selection. The tourism sector is an important sector with its positive contributions to the Gross Domestic Product (GDP) of the region in which it is located, the development of many sectors due to multiplier effect and the increase in employment in these sectors and the contribution of both local and national economy with the increase in foreign exchange inputs.

In this context, the aim of the study is to analyze the role of tourism in the development of the local economy in Van. In addition, the impact of tourism on the development of the local economy and the alternative tourism potential of the city have been revealed and it is aimed to emphasize the importance of tourism in providing economic and social development in the city. In this study, 300 surveys were conducted between November 2018 and April 2019 with Iranian tourists visiting Van city. The contribution of tourism to the economy of the city was tried to be measured by the survey and some suggestions were made within the framework of the result. Data collected in the study SPSS 19.0. program and analyzed.

As a result of the research; The fact that Iranian tourists are close to Van's city and have easy access to transportation, having various freedom areas compared to their own countries, having difficulty in finding goods and services subject to tourist consumption in their countries, and getting rid of the pressure of the current regime, dressing as they wish, and walking around comfortably. Iranian tourists who prefer the city of Van for shopping, shopping and having fun, mostly tourists coming 
with their families and private cars, stay less than a week, visit the city's entertainment venues and shopping malls, and visit the city for an average of $\$ 250-1000$. tourists spend less than 2-3 days because of their stay, tourists are happy to be in the city and will recommend to friends, 39\% of Iranian tourists from noise, 3\% These are the findings obtained from the study in which they are uncomfortable with waste and pollution in public spaces, and $49 \%$ from the intensive construction in the city center and from the trades and tourism enterprises selling some products at exorbitant prices.

The city's cultural heritage, historical and natural beauties, alternative tourism potential and touristic values are important in terms of showing that tourism can develop further if the existing potential is evaluated. Turkey in recent years to move up significant trends in tourism, coastal areas, sea, sand and sun were evaluated in the axis. As a result of this trend, significant investments have been concentrated in these cities. As the perception of tourism and tourists started to change in recent years, the search for alternative tourism started to come to the forefront by separating the tourism movement from the axis of sea, sand and sun which reduced to summer season. The city of Van is seen as an important destination in terms of its tourism potential and alternative tourism resources. For this reason, it is necessary to make investments on a national scale in regions such as Van, which is among the priority regions for development, but which are strong in terms of tourism potential and have opportunities to develop. Tourism investments for the city of Van, which has been one of the priority provinces in local development for years, should be encouraged and financial assistance programs should be put into operation. In addition, travel agencies, accommodation and transportation services and commercial enterprises producing goods and services for tourists are the most important tourism organizations that trigger the development of tourism. The success of these organizations and events leads to increases in tourism revenues in the tourist destination region. In this context, the success factors of tourism in a region are realized through the supportive policies of local and central government of investment and various incentives towards these enterprises. Necessary actions and arrangements should be made in order to provide coordination and coordination among enterprises, to provide cheap and 
long-term credits to increase investment opportunities, to promote the development of the city through tourism by developing the necessary infrastructure and superstructure opportunities, and to participate in the attraction of tourists for routine activities and alternative tourism types.

As a result, it is not enough for local governments to work on tourism activities in Van. In this context, in cooperation with local and central government; In addition to the aforementioned suggestions, it is thought that tourism will be developed and local contribution will be provided by means of solving the problems voiced by the tourists, meeting the expectations, increasing the number of days of tourists accommodation in order to develop tourism in Van.

\section{Kaynakça / References}

Altınok, S., Karaçol, Z. ve Firat, E. (2016). Kalkınmada ArEGe ve inovasyonun önemi: Türkiye örneği. International Conference on Euroasian Economies, http://www.avekon.org/papers/1599.pdf ${ }_{L} \quad$ adresinden 12/08/2018 tarihinde erişilmiştir.

Atmaca, Y. (2018). Yerel kalkınma politikaları ve amaçları doğrultusunda kalkınma ajansları ve uygulanabilirliği, Ed, Yılmaz Demirhan, Seyfettin Aslan, Müslüm Kayacı, Ömer Taylan, ISEPA'18 Bildiriler Kitabl, ss. 427-436.

Bahar, O. (2007). Bölgesel kalkınmada turizm sektörünün ekonomik açıdan yeri ve önemi. Muğla Üniversitesi Sosyal Bilimler Enstitüsü Dergisi, 19, $1-19$.

Eceral, Ö, T. ve Özmen, A, C. (2009). Beypazarı'nda turizm gelişimi ve yerel ekonomik kalkınma. Ekonomik ve Sosyal Araştırmalar Dergisi, 5(2), 4674.

Erdoğan, H. (1995). Ekonomik sosyal kültürel çevresiyle uluslararası turizm. Bursa: Uludağ Üniversitesi Yayınları.

Hazar, A. (2006). Spor ve turizm. Ankara: Detay Yayıncllı.

İçöz, O. (2005). Turizm ekonomisi. (3.Baskı) Ankara: Turhan Kitapevi.

Olalı, H. ve Timur, A. (1986). Turizmin Türk ekonomisindeki yeri. İzmir: Ofis Yayıncilik.

Özmen, A, C. (2007). Yerel ekonomik kalkınma girişimi ve etkileri: Beypazarı örneği. Yayınlanmış Yüksek Lisans Tezi, Gazi Üniversitesi Fen Bilimleri Enstitüsü, Ankara. 
Pektaş, E. K. (2010). Türkiye'de sosyal belediyecilik uygulamaları ve temel sorunlar. Akademik Incelemeler Dergisi, 5 (1), 3-22.

Uğurlar, A. (2006). Turizmin yerel ekonomiye etkileri ve sürdürülebilirliği: Van örneği, Yüksek Lisans Tezi, Gazi Üniversitesi Fen Bilimleri Enstitüsü, Ankara.

Tekeli, İ. (2002). Sivil toplum kuruluşları, yerelleşme ve yerel yönetimler. İstanbul: Tarih Vakfı Yayınları.

Tunçsiper, B. ve Yılmaz, Ö. G. (2009). Yerel ekonomik kalkınma sürecinin turizm sektörüne etkisi. Dumlupınar Üniversitesi Sosyal Bilimler Dergisi, 24, 53-70.

WTO, (World Tourism Organisation). (1995). Collection of tourism expenditure statistics report, https:/www.eunwto.org/doi/book/10.18111/9789284401062 adresinden 18/04/2019 tarihinde erişilmiştir.

Yıldız, Z. (2007). Turizmin bölgesel kalkınmaya să̆ladığı katkılar ve göller bölgesi uygulaması. Yayınlanmamış Doktora Tezi, İstanbul Sosyal Bilimler Enstitüsü. İstanbul.

Zengin, B. (2010). Turizm sektörünün Türkiye ekonomisine reel ve moneter etkileri. Akademik Incelemeler Dergisi, 5(1), 103-126.

\section{Kaynakça Bilgisi / Citation Information}

Yılmaz, V. ve Karaağaç, M. (2019). Turizmin yerel kalkınmadaki öneminin değerlendirilmesi: Van kenti örneği. OPUS-Uluslararası Toplum Araştırmaları Dergisi, 13(19), 2042-2067. DOI:10.26466/opus. 597619 